\title{
Fostering Low English Proficiency Learners' Reading in a Freshman EFL Reading Class: Effect of Using Electronic and Print Textbooks on Taiwanese University Students' Reading Comprehension
}

\author{
Yi-Hsuan Lin ${ }^{1}$, Mei-Rong Alice $\mathrm{Chen}^{2} \&$ Hsiao-Ling $\mathrm{Hsu}^{3}$ \\ ${ }^{1}$ English Department, Chinese Culture University, Taiwan \\ ${ }^{2}$ Graduate Institute of Digital Learning and Education, National Taiwan University of Science and Technology, \\ Taiwan \\ ${ }^{3}$ Institute of Applied English, National Taiwan Ocean University, Taiwan \\ Correspondence: Yi-Hsuan Lin, English Department, Chinese Culture University, Taiwan. E-mail: \\ dianaandcliff@gmail.com
}

Received: August 24, 2020

Accepted: October 2, $2020 \quad$ Online Published: October 31, 2020

doi:10.5539/ijel.v11n1p54

URL: https://doi.org/10.5539/ijel.v11n1p54

\begin{abstract}
This study investigated differences in university students' academic reading comprehension performance, reading strategy use, and perception of the effects of two textbook mediums. Eighty-one students participated in this study. Two textbook formats, hard copies and soft copies of the same textbook were used. A mixed-method research design was used for data collection with paired sample $t$ tests adopted to compare the reading comprehension of two textbooks versions in immediate learning and summative learning on the same group of students, and a questionnaire and semi-structured interviews were employed to probe students' perceptions. The results indicated that the participants performed no differently on the summative reading comprehension tests, but performed significantly better on immediate tests using the e-textbook. The questionnaire and the interviews showed that half of the respondents still preferred to use print compared to e-textbooks. This study concluded that e-textbooks were not yet positioned to replace print textbooks for university students in Taiwan. Nonetheless, pedagogically, since e-textbooks provide more interactive features than print, they should be considered an integral part of reading instruction.
\end{abstract}

Keywords: electronic textbooks, reading strategy, reading comprehension, academic reading

\section{Introduction}

Research on textbook use in higher education has rarely focused on e-book adoption by EFL students who previously used print textbooks to learn English reading. In Taiwan, students with lower proficiency levels tend to be the ones who are less motivated to learn English, and they often have difficulties focusing on learning and lose their interest quickly. The purpose of the study is to investigate whether an e-textbook brings facilitative effects on university students' reading whose English proficiency was low. EFL English teaching is continuously evolving through the adoption of more innovative methods to engage students so that they can become more motivated to learn (Jung et al., 2019; Nopiyanti \& Tarjana, 2019). E-textbooks are treated as a pedagogical tool (Cuillier \& Dewland, 2014). Nonetheless, English educators have not determined whether it is a useful tool for students in the EFL university classroom setting (Chou, 2016; Daniel \& Woody, 2013; Rockinson-Szapkiw et al., 2013).

The significance of the study is to provide suggestions for designing interactive functions on the digital platform to keep readers with lower motivation engaged. The integration of digital reading with English learning might influence students' reading comprehension. An e-textbook with interactive functionality allows teachers to manipulate the textual contents, such as pre-reading questions for students to answer in their e-textbook and know immediately whether their answer is correct to enhance their interests (Lin, 2017). Struggling readers usually show effortful word recognition, a lack of awareness of text organization, a limited repertoire of comprehension strategies, and failure to monitor comprehension (Baker, 1989; Pressley, 2000), which could lead to increased avoidance of English academic reading. The current study focused on instructing low-proficiency learners on the techniques to monitor texts as they read so that they would apply comprehension strategies on the 
interactive e-textbook platform.

As digital features are continually being integrated into regular freshman English reading classes, studies on the use of e-books as instructional and learning tools in the EFL classrooms are still nascent. Technology Acceptance Model (TAM) proposed by Davis Jr. (1985) was adopted in this study. In this model, a number of factors shape ones' intentions about their use of technology. The acceptance of technology could be assessed by asking users about their future intentions to use this technology (Çeçen, 2020; Gasaymeh \& Waswas, 2019). Technology acceptance is related to the users' perceived ease and perceived usefulness. It is important to consider technology and the relation between the actual behaviors of users, perceived usefulness, attitudes, and perceived ease of use (Putra, 2019; Rafique, Bashir, et al., 2020; Verkijika, 2019). The TAM of how users accept and use new technology is applied to investigate e-textbook adoption in the EFL environment. This study adopts an e-book system to offer students and instructors an innovative tool that might enhance the process of developing English reading comprehension. The study aims to:

- compare the instructional effects of using e-textbooks vs. traditional textbooks on Taiwanese university freshman students' performance in reading comprehension summative tests (user behavior);

- investigate the effect of reading-strategy instruction using the interactive multiple-choice questions of the e-textbook platform on Taiwanese university freshman students' performance in reading comprehension formative quizzes (user behavior);

- examine Taiwanese university freshman students' perceptions of the two textbook mediums (perceived usefulness, perceived ease of use, and attitude).

\section{Literature Review}

\subsection{Adoption of Print Versus E-Textbooks as a Teaching Practice}

Recently, reading research on electronic books in comparison to printed books has been growing. Reading from print and reading from digital screens differ significantly in many aspects; for example, digital books grant readers the ability to navigate in the nonlinear medium, while the print books can only lead the readers through the same linear narrative (Eshet-Alkalai \& Chajut, 2010). The past studies that discussed whether digital books affect text comprehension have reported higher perceived cognitive load and lower memory retention when students read digital books, thus comprehending less than when reading print texts (Liu, 2005; Mangen \& van der Weel, 2016). In addition, studies have reported that e-book readers comprehended slower, as paging and scrolling in digital versions extended reading time and decreased information memory (Porion et al., 2016); therefore, numerous studies have concluded in favor of reading print books.

Even though studies on the use of digital content in the classroom as a medium of teaching proliferated, the majority of which investigated how e-books facilitate learning in general (Nelson, 2008; Salajan et al., 2010), but not language learning. In the EFL environment, the reading comprehension between print and e-books are a major concern, as some ambivalent results on reading comprehension were found (Reich et al., 2016). Past studies cannot conclude whether e-book use was positive, negative, or neutral to the second language reading experience (Isaacson, 2017).

Other studies indicated that for digital e-books to work better than print books, student engagement was the key. When students were engaged, they were more likely to read and comprehend more (O’Brien \& Voss, 2011). Krause (2013) claimed that reading education needed to be responsive to dynamic changes in the digital age. Attention should especially be paid to less proficient readers, as they were disadvantaged by the reading materials, and were possibly struggling with digital devices (Harrison, 2016). In academic reading, several studies-controlled paper and screen presentation characteristics to be as similar as possible, and reported the comprehension scores of reading in different formats (Grimshaw \& Dungworth, 2007; Kang et al., 2009). It was found that there was no significant difference between the reading comprehension scores of students reading digital books and those reading print books.

\subsection{Teaching L2 Reading Strategies}

Empirical studies have shown that readers' use of strategies and their reading comprehension are related (Jun Zhang, 2001). Cognitive control processes are critical for reading comprehension; therefore, language learners' successful comprehension depends mainly on intentional reading strategy use.

\subsubsection{Reading Instruction on Strategies in Paper-Based and Electronic Textbooks}

Printed texts are usually designed to be read linearly. The teacher and the students usually browse the text page by page in the pre-reading phase. In the post-reading phase, strategies like question answering, identifying main 
ideas of the passage or the structure of the text, or even summarizing it are encouraged in the classroom. For paper-based textbooks, reading comprehension strategies are taught, and instructions are given. However, the students' behaviors cannot be monitored by the teacher in the classroom individually due to the large class size.

E-textbooks may encourage reading behaviors such as scanning, skimming, information seeking. They also stimulate question-answering because the information can be located and accessed easier. Besides, they render features to digitally manipulate texts. Digital text characteristics such as the layout of the text on the screen could create an environment that makes skimming or highlighting easier and more desirable than printed textbooks. Teachers could design questions so that the students are required to search the text to find answers and build connections between their previous learning and the clues found in the text (Singer \& Alexander, 2017).

\subsection{Assisting Less Proficient EFL Readers}

Less proficient English learners may benefit from the additional tools available with the use of e-books. An e-textbook offers a fresh dimension of reader response, which paper-based textbooks cannot offer. Integrating reading strategies as a featured tool in an e-textbook might improve students' reading comprehension. To comprehend, L2 readers engage in a range of strategic processes and underlying cognitive skills (Van den Broek et al., 2011). In memory-based processes, readers integrate text information with their knowledge about the word and the world to construct a situation model of what the text is about (Van den Broek et al., 2005). Therefore, lower proficiency students' lack of English knowledge, lack of world knowledge, and lack of strategy training had significantly compromised their reading comprehension.

Low proficiency readers usually fail to modulate how they read. These readers are not aware that the reading approach should be changed when reading goals are different (Baker, 1984). They fail to prioritize text understanding over word decoding (Pazzaglia et al., 1995). A vital element for students to improve in L2 reading is teaching them that different tasks involve different demand levels for comprehension. Some tasks require word-level decoding skills to understand details, while other tasks may involve identifying main ideas or supporting information (Grabe \& Stoller, 2014).

When students adjust their way to read for meaning and set a purpose or goal of reading, the goal-related allocation of cognitive resources helps to monitor or repair comprehension. Extant research has proposed various metacognitive strategies to develop learners' metacognition (Costa, 1984). During the reading activity, the reading goals should be made explicitly clear, so the readers plan and internalize what they are required to do to achieve the reading purpose. Two types of reading strategies to clarify reading goals, namely, asking questions and identifying the main idea, would be applied in the present study.

\subsubsection{Asking Questions While Reading}

Questions can be designed to stimulate students' recall of existing knowledge, promote general or detailed comprehension, and enhance critical thinking and analysis. Raphael and Au (2005) stated that students should be asked relevant questions and should be taught to search for answers to the questions that have been formulated to test comprehension. Most of the students needed to be taught to analyze a text from sentence-level understanding and content-level paraphrasing. If the questions can be a guide to help them sieve the essential ideas from non-essential elaboration, holistic representation of the text can be built. Asking the questions is a design of "consciousness-raising" in promoting positive self-perceptions, affect, and motivation among students (Paris \& Winograd, 1990).

\subsubsection{Asking Students to Identify the Main Point of a Passage}

Asking questions helps students set a purpose for reading. When they are instructed to identify the "primary purpose" of the passage, they have a goal to look for information while reading. When the thesis of the passage is identified correctly, the students find out the crux of the author's writing. Studies have shown that asking questions may be most beneficial for lower-level students (Marzano et al., 2001). The students could be trained in identifying the premises to an argument or to grasp the gist of a description.

\subsection{Combining the E-Textbook Platform and Reading Strategy Use for Less Proficient Readers}

Research has implied that readers' interaction with e-textbook content depends on the usability of the e-textbook interface or features (Berg et al., 2010). Compared to print texts, e-textbooks provide interactive features that can be made into an integral part of the reading lesson. Many electronic reading systems offer a platform that permits teachers to personalize the design in order to facilitate students' use of cognitive strategies required in reading activities to support their electronic reading experiences. 


\subsubsection{E-Textbook Platform with Interactive Features}

E-textbooks are potentially more accessible to users, as an e-textbook can be read on any portable or handheld device (deNoyelles \& Raible, 2017). With interactive design and modification, e-textbooks could support students with different cognitive levels. E-textbook platforms permit specific changes, including text presentation and the addition of exercises. The flexibility provided by e-textbooks allows English instructors to integrate the content of English lessons with reading strategies that the instructors intend to teach (Fouh et al., 2014). With a platform that accepts input from students by recording and organizing information, it facilitates English instructors' teaching.

The effects of using different reading strategies to facilitate online reading performances have been investigated (Huang, Chern, \& Lin, 2009; Huang, 2013, Lin, 2019). These studies developed a web-based reading strategy training program based on L2 reading strategy to investigate students' use of the features of the program and their applications of reading strategies. Huang (2013) reported how high and low proficiency level students differ in the adoption of reading strategies. She found that for lower proficiency level students, adopting global strategies significantly contributed to better comprehension. Following a similar line in exploring the reader's strategy use, the present study examines whether lower-proficiency readers' use of the reading strategy of identifying the main ideas, could aid reading comprehension.

\subsubsection{University Students' Perceptions of E-Textbooks and Print Textbooks}

Most of the studies reporting students' perception of e-books were conducted for budgetary reasons, which focused on finding out whether libraries should purchase more e-books (Gregory \& Cox, 2017). This study attempts to examine the acceptance of a new technology being applied in a specific environment, such as the EFL classroom in Taiwan. The relationship between emotional attachment and the attitude or perception of e-textbooks needs to be investigated.

The literature review has identified that in the current environment of higher education in Taiwan, more studies are needed to fill the gap in finding out whether low proficiency students' reading comprehension can be assisted through e-textbook instruction. Three research questions are raised:

1) What is the impact of using e-textbooks vs. traditional textbooks on Taiwanese university freshman students' performance on reading comprehension summative tests?

2) What is the effect of using reading-strategy instruction employing interactive multiple-choice questions of the e-textbook platform on Taiwanese university freshman students' performance on reading comprehension formative quizzes?

3) What is Taiwanese university freshman students' perception of using e-textbooks vs print textbooks for reading comprehension in EFL class?

\section{Method}

A mixed approach was adopted to collect data. Quantitatively, to compare the effects of paper-based textbooks and e-textbooks, in-class formative quizzes and summative test scores were used for paired sample $t$ test analyses. It was hypothesized that students might perform better when e-textbook was involved in the learning process. A five-point Likert-scale questionnaire, and semi-structured interviews were conducted to investigate readers' perception of the e-textbook application. The detailed design and explanation are described as follows.

Before the start of this study, an e-textbook was uploaded and formatted onto the BookRoll system, an e-book platform designed by a professional team at Kyoto University in Japan (Ogata et al., 2015), based on the needs of the instructor. The e-textbook version was designed to look as similar to the traditional print book version as possible. The reading content was displayed page by page in standard orientation. Interactive multiple-choice questions were designed and uploaded by the researchers so that each passage was accompanied by at least one question, which could be repeatedly practiced. This e-textbook also allowed readers to use digital reading tools such as note-taking or adding color highlights.

\subsection{Participants}

The participants of this study were from a private university in Taiwan. They were selected based on convenience sampling from intact freshman English classes taught by one of the researchers. Their English proficiency was substandard, as most of them were unable to meet English proficiency exit requirements from their respective departments to graduate. All freshmen in this university were divided into four levels based on their performance on an English placement exam before the start of the course for university policy. The participants of the present study belonged to the lowest level. To more accurately gauge students' English 
competence, all the participants completed a sample TOEIC exam. Their average TOEIC score was 270 ranging from the highest score of 495 to a lowest score of 195, with a standard deviation of 77.8. Most of the participants were estimated to have a proficiency of A2 level as for the Common European Framework of Reference for Languages (CEFR). Therefore, the participants' English proficiency was ranked elementary based on their TOEIC scores (Qu, Cid, Chan, \& Huo, 2017).

In this study, the design had two conditions: an experimental condition in which all the participants received an e-textbook treatment, and a controlled condition in which they did not. The e-textbook reading was a seven-week project conducted voluntarily. Altogether 81 students participated in the study as they regularly used the e-textbook to read and completed in-class unit-exit quizzes. They used the e-textbook on their mobile devices (e.g., mobile phones, tablets, or laptops) for the reading class for seven weeks. The performance of these participants in the e-textbook and print textbook were compared. The paired-sample $t$-tests (repeated measures) was used in the present study, as the same subjects participated in both conditions of this experiment.

\subsection{Instruments}

\subsubsection{The Use of Reading Textbooks}

The freshman English classes were conducted using the textbook, Reading for Today 3: Issues for Today, published by National Geographic (Smith \& Mare, 2011). The participants used the conventional print textbook for seven weeks from the beginning of the semester. During this period the chapters for the mid-term exam were covered. The lessons covered for the mid-term exam were Chapter Seven: "Solving Crimes with Modern Technology," Chapter Eight: "The Reliability of Eyewitnesses," and Chapter 11: "Objects from Space: Hits and Misses."

After the mid-term exam, the students used the e-textbook for another seven weeks. The e-textbook had a web-based platform, and all the students were connected to their course materials on the online interface through the Internet. For the final exam, Chapter Nine: "Innocent until Proven Guilty," Chapter 10: Saving Lives with New Organs," and Chapter 12: Medicine Today" were covered. The readability of the chapters covered before and after the mid-term exams was of the same level: both on Flesch-Kincaid grade level nine.

\subsubsection{The Design of the Platform Interface}

In the e-textbook platform, the users were able to see each passage in the chapters accompanied by at least one multiple-choice question uploaded by the researchers. These multiple-choice questions displayed on the platform can be repeatedly practiced by students using a drop-down menu. They needed to choose the best answer to each question and fill in the corresponding ovals on the interface of their mobile device (see Figure 1). All the digital reading tools provided by the e-textbooks were made available to the students who logged in.

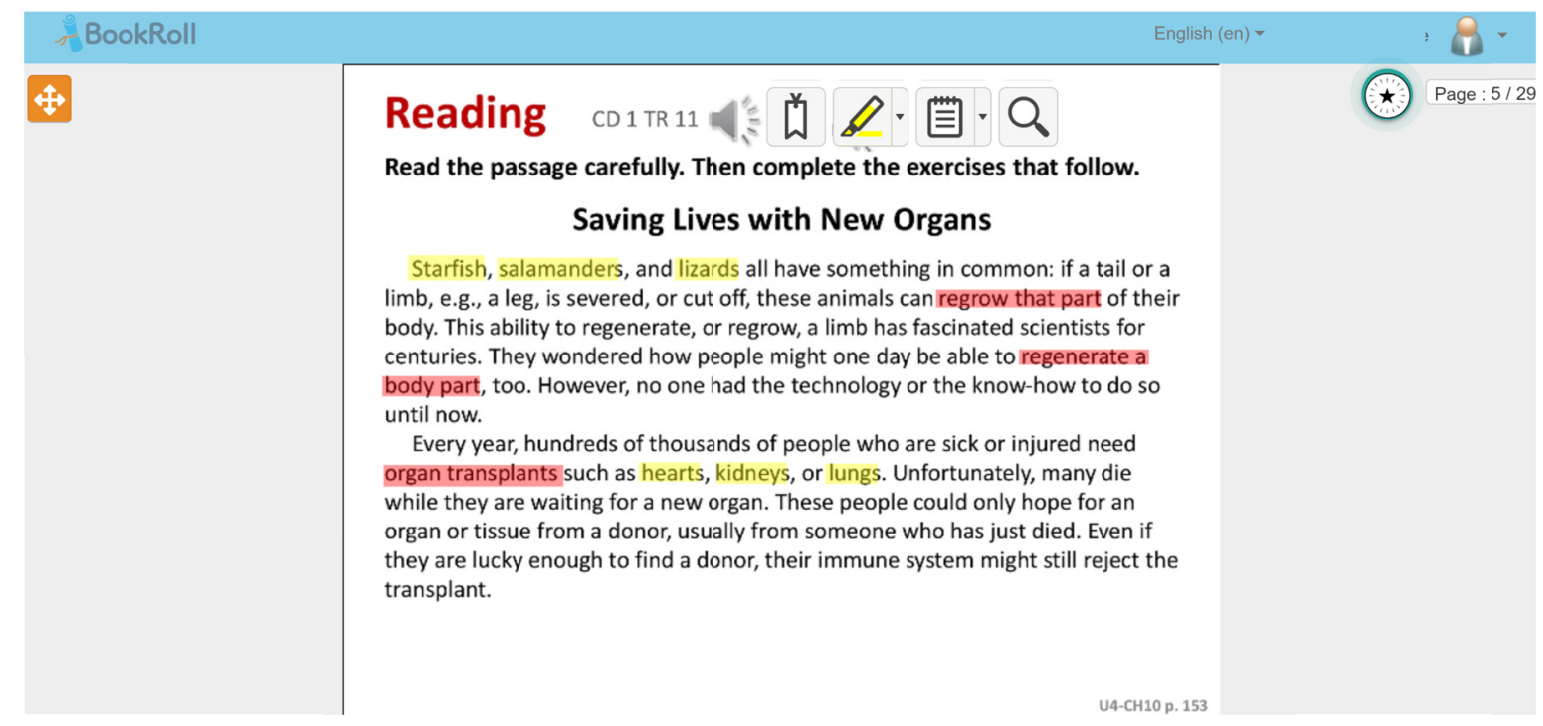

Figure 1. Students' platform interface 


\subsubsection{On-Screen Multiple-Choice Questions to Identify Main Ideas}

The design of the multiple-choice questions was to confirm students' ability to identify main ideas. With repeated practice on the mobile device, students were trained to think in a more encompassing way to summarize each paragraph and to find support for the arguments in the paragraph.

\subsubsection{Questionnaire Probing Students' Perceptions of E-textbook Use}

A perception questionnaire was distributed to collect students' feedback and perceptions of e-textbook use. The participants' feedback was measured by the items. These items are: their past experiences of using digital readers, the usefulness of tools on the interface, the comparison between paper-based textbooks and e-textbooks (Murphy et al., 2003; Thong et al., 2004), and students' behavioral intentions of e-textbooks. These intentions indicate that whether they will increase e-textbook reading and whether they are willing to use e-textbooks to assist future English learning (Hernon et al., 2006; Lin \& Yueh, 2012). A five-point Likert scale was applied to evaluate students' responses, the reliability of which was tested using Cronbach's alpha, a measure of internal consistency. The reliability of the questionnaire was high $(\alpha=0.92)$. It confirmed that the scale items are unidimensional to the participants, and additional analyses could be performed using all the scale items.

\subsubsection{Selection of Interviewees and Questions Design}

Six students who participated in this project were invited for a semi-structured interview, and each participant was assigned a pseudonym. Three interviewees were selected based on their academic performances from the mid-term exam. The high performers (ranking among the top ten of the class) were selected. The other three interviewees were chosen for the reason that they spent more time on electronic books (the platform records showed them as the most frequent users). The decision to invite higher academic performers and frequent e-book users was that they tended to be dedicated and hard-working students among the participants.

The interview questions were derived from the study objectives, which were to probe how the students perceive the effects of reading in the two mediums (Elshahawy, 2020). The structure of the interview questions was based on the questionnaire in Table 3 presented in the Results section. The interviewees were asked to elaborate on their responses to attain detailed and descriptive information on their e-textbook use.

\subsubsection{Lesson Quizzes and Summative Reading Tests}

To compare the effects of reading comprehension between print textbook and e-textbook for English reading instruction, two tools of assessment were designed. First, in-class lesson quizzes were administered after the teaching of each chapter. Their purpose was to evaluate students' immediate learning effect in relation to the two instructional mediums: digital textbook versus a print textbook. In each lesson, a ten-paragraph article was reduced to two passages of main ideas in the form of a cloze test to assess the learning effects in the classroom with the contents of that specific article. The participants needed to organize, synthesize, and integrate the contents in order to fill in the cloze test in each quiz. Consequently, six lesson quizzes were administered three lesson quizzes covering material before the mid-term exam, and the other three lesson quizzes covering material that appeared on the final exam. The cloze questions were provided by the textbook Reading for Today 3: Issues for Today (Smith \& Mare, 2011), and revised by the two experienced instructors. Each quiz had a total score of 100. The Cronbach's alpha value of the in-class quiz lesson test was 0.80 . To check the validity of both lesson quizzes and summative reading tests, two teachers carefully checked whether the test items matched with the relevant test specifications and lesson objectives. They discussed and revised the questions to make the test valid for reading comprehension.

Secondly, summative comprehension tests were administered after seven weeks of print textbook reading and the subsequent seven weeks of digital textbook reading. Each summative test consisted of 30 multiple-choice questions. Both of the summative reading tests were provided by the textbook Reading for Today 3: Issues for Today (Smith \& Mare, 2011) and revised by the two experienced instructors. The total score for both tests was 100. The Cronbach's alpha value of the reading comprehension test is 0.86 .

\subsection{Data Collection Procedure}

The experiment was conducted in the spring semester of 2019. Each meeting for both mediums of instruction lasted for two hours. The first summative learning test based on the first three chapters was administered at the eighth meeting. The second summative learning test based on the latter three chapters was administered at the 16 th meeting.

During the 14-week duration of instruction, in-class lesson quizzes were administered after each chapter was taught. Roughly every other week, a lesson quiz on a single chapter was administered. Three quizzes were 
administered for paper-based textbook reading and the other three quizzes for digital reading. When reading in print, the students took notes and highlighted the texts on their own, the teacher then discussed the main ideas with the class. When reading in the e-textbook, the students took notes and highlighted the texts digitally on their screen. The questionnaire was administered during the final week of the semester. The semi-structured interviews were conducted after the final week. During the interview data analysis, contents related to "past experiences", "usefulness of two media", "comparison between two textbooks", "users' behaviors", and "English learning" were specifically identified and the common or similar statements mentioned frequently or mentioned by most of the interviewees were used as example to report on the qualitative findings. For the data analysis on the tests, two statistical $t$ tests were performed to compare the results between the in-class quizzes, and the summative tests on the participants' reading comprehension of print-textbooks and e-textbooks. For the data analysis on the questionnaire, the researchers examined the mean and standard deviation as there was a series of Likert-type questions that were combined to describe the attitude and perception of print-textbook and e-textbook use.

\section{Results}

For the first research question, the researchers investigated whether e-textbook reading yielded better comprehension outcomes than paper-based reading by conducting a paired sample $t$ test. A statistical comparison of different forms of instructional materials was applied to the same group of participants to answer the first research question regarding the effects of using e-textbook and a print textbook on reading comprehension. There were two comprehension tests on their summative learning, one conducted after the participants were instructed with paper-textbook, and the other after the participants were instructed using e-textbooks. Table 1 showed that there was not a significant difference in the scores for reading comprehension of a print textbook $(M$ $=73.0, S D=19.1)$ and of e-textbook $(M=76.0, S D=23.1)$ conditions, $t(80)=1.10, p=.273, d=0.14$. The participants did not comprehend better when the reading processes involved a screen.

Table 1. Results of the paired-sample $t$ test for reading comprehension

\begin{tabular}{llllll}
\hline Group & $N$ & $M$ & $S D$ & $t$ & Cohen's $d$ \\
\hline e-textbook & 81 & 76.0 & 23.1 & 1.10 & 0.141 \\
print-textbook & 81 & 73.0 & 19.1 & & \\
\hline
\end{tabular}

As for the second research question, the researchers investigated whether the multiple-choice question feature of the e-textbook yields significantly better strategy learning (identification of main ideas) than post-reading questions in the printed textbook. A paired-sample $t$ test was conducted to compare the average of the three in-class quiz scores respective to the paper and digital textbook conditions. Table 2 shows a significant difference in the scores of quizzes for print $(M=77.0, S D=11.4)$ and electronic $(M=86.2, S D=10.4)$ textbook conditions, $t(80)=7.23, p<.001, d=0.84$. The statistical results showed that strategy-teaching using the interactive multiple-choice questions on the platform facilitated learning of the strategy of main idea identification.

Table 2. Results of the paired-sample $t$ test for lesson quizzes

\begin{tabular}{llllll}
\hline Group & $N$ & $M$ & $S D$ & $t$ & Cohen's $d$ \\
\hline e-textbook & 81 & 86.2 & 10.4 & 7.23 & 0.843 \\
paper-textbook & 81 & 77.0 & 11.4 & & \\
\hline
\end{tabular}

To answer the third question regarding the questionnaire of readers' perception of the usage of print textbooks and e-textbooks in the English class, Table 3 showed that even though most students were familiar with digital readers (61\% agreed or strongly agreed), they expressed only mid-level positive attitudes toward e-textbooks in perceived usefulness, as seen in the statement on questionnaire that "I am satisfied with the functions of this e-textbook" $(M=3.3, S D=1.2)$. When asked to compare the e-textbook and print textbook in the statement "given a choice between an electronic or print version of a particular textbook, I will choose the electronic version" ( $M=2.6, S D=1.2)$, about $46 \%$ of participants disagreed or strongly disagreed, implying that almost half of the students preferred print over electronic textbook (see Table 3). 
Table 3. Participants' perceptions toward e-textbook and print textbook

\begin{tabular}{|c|c|c|c|c|c|c|c|c|}
\hline & Question items & $\begin{array}{l}\text { Strongly } \\
\text { disagree }\end{array}$ & Disagree & Neutral & Agree & $\begin{array}{l}\text { Strongly } \\
\text { agree }\end{array}$ & $M$ & $S D$ \\
\hline & & $\begin{array}{l}1 \\
(\%)\end{array}$ & $\begin{array}{l}2 \\
(\%)\end{array}$ & $\begin{array}{l}3 \\
(\%) \\
\end{array}$ & $\begin{array}{l}4 \\
(\%)\end{array}$ & $\begin{array}{l}5 \\
(\%) \\
\end{array}$ & & \\
\hline \multirow[t]{3}{*}{$\begin{array}{l}\text { Past } \\
\text { experiences }\end{array}$} & $\begin{array}{l}\text { 1. I am familiar with digital } \\
\text { readers. }\end{array}$ & 0 & 17.3 & 22.2 & 35.8 & 24.7 & 3.7 & 1.0 \\
\hline & $\begin{array}{l}\text { 2. I have read e-books on } \\
\text { my computer or tablets before. }\end{array}$ & 22.2 & 21.0 & 18.5 & 22.2 & 16.0 & 2.9 & 1.4 \\
\hline & $\begin{array}{l}\text { 3. I have read e-books on } \\
\text { my mobile phones before. }\end{array}$ & 3.7 & 16.0 & 16.0 & 27.2 & 37.0 & 3.8 & 1.2 \\
\hline \multirow[t]{4}{*}{ Usefulness } & $\begin{array}{l}\text { 4. I used the (highlighting) } \\
\text { colors in this e-textbook. }\end{array}$ & 8.6 & 18.5 & 40.7 & 18.5 & 13.6 & 3.1 & 1.1 \\
\hline & $\begin{array}{l}\text { 5. The font size and typeface } \\
\text { in this e-book were easy to read. }\end{array}$ & 8.6 & 17.3 & 46.9 & 16.0 & 11.1 & 3.0 & 1.1 \\
\hline & $\begin{array}{l}\text { 6. I took notes on this } \\
\text { e-textbook. }\end{array}$ & 11.1 & 23.5 & 24.7 & 23.5 & 17.3 & 3.1 & 1.3 \\
\hline & $\begin{array}{l}\text { 7. I am satisfied with the } \\
\text { functions of this e-textbook. }\end{array}$ & 2.5 & 27.2 & 28.4 & 21.0 & 21.0 & 3.3 & 1.2 \\
\hline \multirow[t]{2}{*}{$\begin{array}{l}\text { Comparison } \\
\text { between } \\
\text { books }\end{array}$} & $\begin{array}{l}\text { 8. Given a choice between } \\
\text { an electronic or print version of } \\
\text { a particular textbook, I will } \\
\text { choose the electronic version. }\end{array}$ & 24.7 & 21.0 & 30.9 & 16.0 & 7.4 & 2.6 & 1.2 \\
\hline & $\begin{array}{l}\text { 9. It was easier to find } \\
\text { important information in the } \\
\text { e-book. }\end{array}$ & 8.6 & 17.3 & 38.3 & 21.0 & 14.8 & 3.2 & 1.1 \\
\hline \multirow[t]{3}{*}{$\begin{array}{l}\text { Behavioral } \\
\text { intention }\end{array}$} & $\begin{array}{l}\text { 10. I intend to increase my } \\
\text { use of e-books. }\end{array}$ & 12.3 & 23.5 & 29.6 & 19.8 & 14.8 & 3.0 & 1.2 \\
\hline & $\begin{array}{l}\text { 11. In five years, I will do } \\
\text { most of my reading from } \\
\text { e-books }\end{array}$ & 23.5 & 29.6 & 28.4 & 13.6 & 4.9 & 2.5 & 1.1 \\
\hline & $\begin{array}{l}\text { 12. I intend to use e-books to } \\
\text { assist my future learning. }\end{array}$ & 14.8 & 22.2 & 34.6 & 16.0 & 12.3 & 2.9 & 1.2 \\
\hline \multirow[t]{3}{*}{$\begin{array}{l}\text { English } \\
\text { learning }\end{array}$} & $\begin{array}{l}\text { 13. This e-textbook (with } \\
\text { multiple choices) has helped me } \\
\text { grasp the main ideas of text. }\end{array}$ & 2.5 & 8.9 & 41.7 & 24.8 & 22.1 & 3.5 & 1.0 \\
\hline & $\begin{array}{l}\text { 14. This E-textbook has } \\
\text { helped me find the keywords in } \\
\text { detail. }\end{array}$ & 2.5 & 9.9 & 40.7 & 24.7 & 22.2 & 3.5 & 1.0 \\
\hline & $\begin{array}{l}\text { 15. This E-textbook has } \\
\text { facilitated my English learning. }\end{array}$ & 1.2 & 24.7 & 30.9 & 21.0 & 22.2 & 3.4 & 1.1 \\
\hline
\end{tabular}

For perceived behavioral intention, statements eight to twelve on Table 3 have reflected that physical copies of books for reading were still preferable when compared to e-books. For instance, in "I intend to increase my use of e-books," approximately $36 \%$ of the respondents strongly disagreed or disagreed with this statement. About $30 \%$ of the respondents did not have a specific preference, revealing that half of the participants were still likely to buy and use print textbooks in the future. As for English learning, on statements thirteen to fifteen, the result was ambiguous about whether e-textbook had positive or negative effects on English learning. Only $43 \%$ of the students strongly agreed or agreed with the statement that "this e-textbook has facilitated my English learning". In summary, although most students had experiences with digital readers, they held a mid-level positive attitude toward the usefulness or the effect the e-textbooks brought upon learning.

The interview data found that in usefulness, all six interviewees expressed that it was not necessary to use e-textbooks unless there were considerably advantageous features. An interviewee, by the pseudonym of Andy, elaborated on this point: "Unless the e-textbook automatically translates texts into Chinese, I did not think e-textbooks have an upper-hand over print books for us, low proficiency learners."

As for the reasons they thought that some students preferred digital books, a couple of interviewees mentioned "portability" as Mia commented that "it could be that digital books have better portability." Despite the convenience, e-textbooks brought eyestrain problems upon students. Most of the interviewees reported that 
eyestrain was one reason for their unwillingness to read e-textbooks. Andy said, "I do not have a laptop or a tablet, so reading on mobile phones was a problem when I needed to read and re-read materials intensively in class, for I had to stare at the screen for a long time... I think glaring on-screen is tiring."

When comparing e-textbooks with conventional textbooks, four out of six interviewed students preferred print textbooks. The benefits mentioned for print textbooks included, "neither the Internet access nor a digital device is required to read the textbook (Andy)," and "With no e-reading device such as a tablet to take to school, it could be more cost-effective to choose a paper-based textbook" (Olivia). For e-textbook reading, you need to be equipped with reading devices." One interviewee added, "Besides, we still take exams on paper-form, so reading and writing on real paper seems to be more convenient for us. Most of us are used to doing academic affairs on paper" (Andy). And, "reading on paper, with real pages that I can turn with my fingers, I felt like I did more deep reading, as I worked through a text, I know how much more reading is left for me to finish" (Emma). The final statement seemed to indicate that the movements of flipping through pages appeared to notify them about the number of pages already read, and helped them gauge their reading progress.

In reporting what they liked about reading textbooks in hard copies, respondents mentioned, "I concentrate better on print textbooks" (Andy) and "the content stays in my head longer when reading print books" (Olivia). One interviewee, Emma, warned the interviewer "Do you know some of our classmates used mobile phones in class doing 'multi-tasking' during lecturing? They do not concentrate on our e-textbook! I saw the boy in the second row, chatting online!" Such responses implied that allowing students to use digital devices in class distracted learning. For future behavioral intentions, again, four interviewees expressed in the interview that they desired paper-based textbooks. For instance, Emma said, "Given the choice, for the time being, I prefer paper-based textbooks." Two interviewees mentioned that they would be open to both printed and digital formats. Mia said, "I think both kinds of books have their advantages and disadvantages." While Nancy stated, "In the future, the combinations of paper and digital textbooks will be available in the market since more and more students have tablets."

When the factor of language learning came into play, foreign-language proficiency was a concern for all interviewees. Three out of the six interviewees explained that if they read in Chinese, reading on a computer screen would be more tolerable since they read Chinese texts faster than English. They like the interactive multiple-choice design on the platform, and four students agreed that it was an excellent design. As Nancy explained, "I paid more attention when I needed to answer the questions on the platform," and Olivia also said, "I think this platform taught me to be mindful in my reading, so I know where the key points are in the text."

\section{Discussion}

For the first research question regarding the comprehension results between the print textbook and e-textbook, the results of summative learning tests of reading comprehension indicated that the participants scored statistically the same. Some essential findings shed new light on the similarities and differences between reading print and digital content for university students in an EFL context.

\subsection{Both Print/E-Textbook Reading Requires Training on Reading Skills}

Since the participants performed equally on both textbook mediums on summative reading tests, the present study was in line with some literature on reading comprehension on paper and screen (Grimshaw \& Dungworth, 2004; Kang et al., 2009; Singer \& Alexander, 2017). To learn from e-textbooks requires the same basics of comprehension skills and vocabulary as with print textbooks. From the results of the present study, in the long learning period, it did not matter which medium the teacher adopted for the academic reading class (Daniel \& Woody, 2013). Plausibly, the information might be processed similarly. Therefore, to increase understanding for EFL learners, learning how to use a range of different reading skills is more important than choosing a different medium of textbooks.

\subsection{Interactive Platform Increased Students' Attentiveness and Engagement with Classroom Materials}

As for the second research question regarding the instructional effects of strategy teaching via e-textbook question prompts on the platform, the statistical results showed that this treatment significantly increased their comprehension as measured by in-class quizzes. The low proficiency level students could better utilize global strategies in reading (Huang, 2013). The level of engagement of the learners in the reading process was higher when the instructor used the interactive platform. The result was in line with the findings from literature review (Fouh et al., 2014; Lin, 2019). Since the class for freshman English was large, consisting of more than 60 students for one class, with the help of the interactive platform, the students could practice the questions and self-correct without the teacher's supervision. 


\subsection{Reserved Attitude Toward E-Textbooks}

Regarding the third research question on students' perception of the usage of print textbooks and e-textbook, students' self-reports tended to indicate that e-textbooks are not that popular among EFL learners. The present study gave our participants equal time to read and learn with both text media, allowing for the comparison of the advantages and disadvantages of digital and print textbooks. The end-of-semester questionnaire and interviews indicated that although the majority of the participants were experienced digital readers and were in general receptive to e-textbooks, the participants did not overwhelmingly prefer to read digitally. The finding reflected what was mentioned in the studies such as Nopiyanti and Tarjana (2019) and also Verkijika (2019). Even with the same note-taking and highlighting features as print books, roughly half of them still preferred conventional paper textbooks.

Even though our respondents praised the digital textbook for its portability, for English learning, not many participants strongly felt e-textbooks have a positive effect, the similarities can be found in Elshahawy's (2020) study. It can be concluded that the respondents preferred print textbooks on several counts. First, our readers grew tired of reading on the screen; the exhaustion could have an adverse effect on both reading comprehension and also their preferences for e - textbooks. In further discussing their perceptions of e-textbooks in the interview, many of the critical remarks were discovered to refer to the e-book's distraction. Reading digitally appeared to encourage multitasking both in class and at home. Moreover, some participants claimed that they "learned better" from the printed version. Free from online distractions, they felt they absorbed more, and they could re-read the texts or sentences in any order they wanted and jumped from pages to highlight and organize information. According to the students, these things helped trigger their memory when they wrote in the paper-based exams.

\subsection{E-Book Access and Diversity of Reading Habits Affect Their Attitude Toward Print/E-Textbook}

This study has found that several students thought access to e-textbook was an issue in the classroom because not all students were equipped with the proper reading devices, which might interfere with their decision to use e-textbooks. In Taiwanese universities, the teacher could not ensure uniform access to a digital reader. Thus, a divide possibly related to socioeconomic status may exist in the nature of information technology use. As a result, the relationship between the effects and the preference for digital reading may be a product of contexts such as whether the students have sufficient exposure to digital readers (Verkijika, 2019).

Additionally, for many students, using physical books, pens, and papers are still daily habits. Even though technology is changing, it might be hard to break the habit of reading the pages of a physical textbook. Some students might get used to carrying tablets that allow them to take notes at the same time, but still, a certain amount of them preferred the tactile experience of reading a printed book. This reflected the point raised by Mangen et al. (2016) that reading in print involves different manual actions and tactile experiences from reading in digital materials. Printed books provide more kinesthetic feedback, so readers feel that they are more efficient to locate events in the space of the text.

\section{Conclusion}

This study addressed whether students learn as much or even better when they read e-textbooks for English reading. The findings showed that the participants scored about the same when reading in each medium. However, the findings also indicated that the participants performed better on quizzes when they were taught reading strategies from the platform using the e-textbook. This has demonstrated that technology integration might be appropriate for teaching reading content. When the students were provided with questions utilizing specific reading strategies to comprehend the content, they were motivated to answer the questions as they went along through the chapter. There was no wait-time between reading and answering questions when they read on-screen with the digital device.

In this vein, it is suggested that an interactive digital system can be used to facilitate lower-proficiency readers, especially when the English classes are large. Technology provides a way for students to think about their responses as they read. It helps teachers to adjust the teaching material and helps students to gain access to that material. With a digital system, sustained engagement can be supported to help students experience a different facet of learning via interactive questions embedded in the e-textbook platform. By so doing, engagement can be tailored to meet the class needs and adjusted to students' reading proficiency levels much easier than with paper-based books.

When the participants were queried about their reading preferences, the findings were particularly revealing in that the students were far from ready to give up conventional print textbooks. Whereas an English passage 
displayed on an electronic textbook and in a paper-based textbook may be similar concerning visual properties. For example, where the sequence of the text may look very much alike on paper and on-screen, the two mediums differ significantly when university learners read. When reading on paper, students felt much more like "real studying." For most students, manipulating a print textbook gave them a sense of where they were in the textbook, so they could know how much more they needed to study.

This study has shown that challenges remain in terms of making e - textbooks more acceptable for university students in an EFL context. Even though certain features make reading digitally an inviting option, i.e., an interactive platform, most students might use e-textbooks only when the e-textbooks are easier to navigate and also reduce their eye fatigue. The features in e-textbooks should be improved further to increase the likelihood of the e-textbooks being used in a university.

\section{References}

Baker, L. (1984). Spontaneous versus instructed use of multiple standards for evaluating comprehension: Effects of age, reading proficiency, and type of standard. Journal of Experimental Child Psychology, 38, 289-311. https://doi.org/10.1016/0022-0965(84)90127-9

Baker, L. (1989). Metacognition, comprehension monitoring, and the adult reader. Educational Psychology Review, 1, 3-38. https://doi.org/10.1007/BF01326548

Berg, S. A., Hoffmann, K., \& Dawson, D. (2010). Not on the same page: Undergraduates' information retrieval in electronic and print books. The Journal of Academic Librarianship, 36(6), 518-525. https://doi.org/10.1016/j.acalib.2010.08.008

Çeçen, G. (2020). Tertiary level EFL students' perceptions regarding the use of Edmodo, Quizlet, and Canva within technology acceptance model (Tam). Doctoral dissertation, Bilkent University. Retrieved from https://www.academia.edu/download/57420778/TAM_Review.pdf

Cheryl, A. C., \& Jason, C. D. (2014). Understanding the key factors for e-textbook integration into a Business course: A case study. Journal of Business \& Finance Librarianship, 19(1), 32-60. https://doi.org/10.1080/08963568.2013.824338

Chou, I. (2016). Reading for the purpose of responding to literature: EFL students' perceptions of E-books. Computer Assisted Language Learning, 29(1), 1-20. https://doi.org/10.1080/09588221.2014.881388

Chou, S. C., Stu, J., \& Lin, Y. (2010). Determinants of ebook readers adoption and continuation: A comparison of pre-adoption and post-adoption beliefs. In Proceedings of the 5th International Conference on Computer Sciences and Convergence Information Technology. https://doi.org/10.1109/ICCIT.2010.5711176

Costa, A. L. (1984). Mediating the metacognitive. Educational Leadership, 42(3), 57-62. Retrieved from https://eric.ed.gov/?id=EJ310031

Cuillier, C. A., \& Dewland, J. C. (2014). Understanding the key factors for e-textbook integration into a business course: A case study. Journal of Business \& Finance Librarianship, 19(1), 32-60. https://doi.org/10.1080/08963568.2013.824338

Daniel, D. B., \& Woody, W. D. (2013). E-textbooks at what cost? Performance and use of electronic v.s. print texts. Computers \& Education, 62, 18-23. https://doi.org/10.1016/j.compedu.2012.10.016

Davis, F. D. (1985). A technology acceptance model for empirically testing new end-user information systems: Theory and results. Doctoral dissertation, Massachusetts Institute of Technology. DSpace@MIT. Retrieved from http://hdl.handle.net/1721.1/15192

deNoyelles, A., \& Raible, J. (2017). Exploring the use of e-textbooks in higher education: A multiyear study. Educause. https://er.educause.edu/articles/2017/10/exploring-the-use-of-e-textbooks-in-higher-education-a-multiyear-s tudy

Elshahawy, K. E. M. (2020). Practicing English Through Digital Devices: Practices and Perceptions of the EFL Undergraduate Students Majoring in English Language. International Journal of Language and Literary Studies, 2(1), 21-37. https://doi.org/10.36892/ijlls.v2i1.109

Eshet-Alkalai, Y., \& Chajut, E. (2010). You can teach old dogs new tricks: The factors that affect changes over time in digital literacy. Journal of Information Technology Education, 9, 173-181. https://doi.org/10.28945/1186

Fouh, E., Breakiron, D. A., Hamouda, S., Farghally, M. F., \& Shaffer, C. A. (2014). Exploring students learning 
behavior with an interactive e-textbook in computer science courses. Computers in Human Behavior, 41, 478-485. https://doi.org/10.1016/j.chb.2014.09.061

Gasaymeh, A. M., \& Waswas, D. M. (2019). The use of TAM to investigate university students' acceptance of the formal use of smartphones for learning: A qualitative approach. International Journal of Technology Enhanced Learning, 11(2), 136. https://doi.org/10.1504/IJTEL.2019.098756

Grabe, W., \& Stoller, F. (2014). Teaching reading for academic purposes. In M. Celce-Murcia, D. Brinton \& M. Snow (Eds.), Teaching English as a second or foreign language (4th ed., pp. 189-205). National Geographic Learning.

Gregory L., \& Cox L. (2017). Remember when e-books were all the rage? A look at student preferences for printed versus electronic text ( $\mathrm{pp}$. 77-83). In Proceedings of the Informing Science and Information Technology Education Conference, Vietnam. Informing Science Institute. https://doi.org/10.28945/3731

Grimshaw, S., Dungworth, N., McKnight, C., \& Morris, A. (2007). Electronic books: Children's reading and comprehension. British Journal of Educational Technology, 38(4), 583-599. https://doi.org/10.1111/j.1467-8535.2006.00640.x

Harrison, C. (2016). Are computers, smartphones, and the Internet a boon or a barrier for the weaker reader? Journal of Adolescent \& Adult Literacy, 60(2), 221-225. https://doi.org/10.1002/jaal.569

Hernon, P., Hopper, R., Leach, M. R., Saunders, L. L., \& Zhang, J. (2006). E-book use by students: Undergraduates in economics, literature, and nursing. The Journal of Academic Librarianship, 33(1), 3-13. https://doi.org/10.1016/j.acalib.2006.08.005

Huang, H. (2013). Online reading strategies at work: What teachers think and what students do. ReCALL, 25(3), 340-358. https://doi.org/10.1017/s0958344013000153

Huang, H., Chern, C., \& Lin, C. (2009). EFL Learners' use of online reading strategies and comprehension of texts: An exploratory study. Computers \& Education, 52(1), 13-26. https://doi.org/10.1016/j.compedu.2008.06.003

Isaacson, S. A. (2017). The impact of interface on ESL reading comprehension and strategy use: A comparison of e-books and paper texts. TESOL Journal, 8(4), 850-861. https://doi.org/10.1002/tesj.357

Jun Zhang, L. (2001). Awareness in reading: EFL students' Metacognitive knowledge of reading strategies in an acquisition-poor environment. Language Awareness, $268-288$. https://doi.org/10.1080/09658410108667039

Jung, Y. J., Cho, K., \& Shin, W. S. (2019). Revisiting critical factors on teachers' technology integration: the differences between elementary and secondary teachers. Asia Pacific Journal of Education, 39(4), 548-561. https://doi.org/10.1080/02188791.2019.1620683

Kang, Y., Wang, M., \& Lin, R. (2009). Usability evaluation of e-books. Displays, 30(2), 49-52. https://doi.org/10.1016/j.displa.2008.12.002

Krause, M. B. (2013). A series of unfortunate events: The repercussions of print- literacy as the only literacy for talented boys. Gifted Child Today, 36(4), 237-245. https://doi.org/10.1177/1076 217513501805

Lin, C. (2017). Learning English with electronic textbooks on tablet PCs. Interactive Learning Environments, 25(8), 1035-1047. https://doi.org/10.1080/10494820.2016.1242505

Lin, J. (2019). Factors Related to EFL/ESL Learners' Reading Strategy Use: A Literature Review. Chinese Journal of Applied Linguistics, 42(1), 92-112. https://doi.org/10.1515/CJAL-2019-0006

Lin, W. J., \& Yueh, H. P. (2012). Examining college students' reading behaviors and needs for e-book readers. Journal of Library and Information Studies, 10(2), 13-142.

Liu, Z. (2005). Reading behavior in the digital environment: Changes in reading behavior over the past ten years. Journal of Documentation, 61(6), 700-712. https://doi.org/10.1108/00220410510632040

Mangen, A., \& van der Weel, A. (2016). The evolution of reading in the age of digitisation: An integrative framework for reading research. Literacy, 50, 116-124. https://doi.org/10.1177/1075547003259209

Marzano, R., Pickering, D., \& Pollock, J. (2001). Classroom instruction that works: Research-based strategies for increasing student achievement. Association for Supervision and Curriculum Development.

Murphy, P. K., Long, J. F., Holleran, T. A., \& Esterly, E. (2003). Persuasion online or on paper: A new take on an old issue. Learning and Instruction, 13(5), 511-532. https://doi.org/10.1016/S0959-4752(02)00041-5 
Nelson, M. R. (2008). E-books in higher education: Nearing the end of the area of hype? Educause Review, 43(2), 40-56.

Nopiyanti, H., Asib, A., \& Tarjana, S. S. (2019). The Students and Teacher's Views on the Use of E-textbooks in Reading Classroom. Journal of English Education, 4(1), 1-15. https://doi.org/10.31327/jee.v4i1.859

O'Brien, D., \& Voss, S. (2011). Reading multimodally: What is afforded? Journal of Adolescent \& Adult Literacy, 55(1), 75-78.

Ogata, H., Yin, C., Oi, M., Okubo, F., Shimada, A., Kojima, K., \& Yamada, M. (2015). E-book-based learning analytics in university education (pp. 401-406). In Proceedings of the 23rd International Conference on Computers in Education. Retrieved from https://kyushu-u.pure.elsevier.com/en/publications/e-book-based-learning-analytics-in-university-education

Paris, S. G., \& Winograd, P. (1990). How metacognition can promote academic learning and instruction. In B. F. Jones \& L. Idol (Eds.), Dimensions of Thinking and Cognitive Instruction (1st ed., pp. 15-51). Lawrence Erlbaum Associates.

Pazzaglia, F., De Beni, R., \& Cornoldi, C. (1995). Metacognitive knowledge about reading and self-esteem in poor readers. Advances in Learning and Behavioral Disabilities, 9, 91-117.

Porion, A., Aparicio, X., Megalakaki, O., Robert, A., \& Baccino, T. (2016). The impact of paper-based versus computerized presentation on text comprehension and memorization. Computers in Human Behavior, 54, 569-576. https://doi.org/10.1016/j.chb.2015.08.002

Pressley, M. (2000). What should comprehension instruction be the instruction of? In M. L. Kamil, P. B. Mosenthal, P. D. Pearson \& R. Barr (Eds.), Handbook of reading research (Vol. 3, pp. 545-561). Lawrence Erlbaum Associates.

Putra, I. D. G. R. D. (2019). The evolution of technology acceptance model (TAM) and recent progress on technology acceptance research in ELT: State of the art article. Yavana Bhasha: Journal of English Language Education, 1(2). https://doi.org/10.25078/yb.v1i2.724

Qu, Y., Cid, J., Chan, E., \& Huo, Y. (2017). Statistical Analyses for the Expanded TOEIC® Speaking Test. ETS Research Memorandum Series, 1-11. https://doi.org/10.1002/ets2.12180

Rafique, H., Almagrabi, A. O., Shamim, A., Anwar, F., \& Bashir, A. K. (2020). Investigating the acceptance of mobile library applications with an extended technology acceptance model (TAM). Computers \& Education, 145, 103732. https://doi.org/10.1016/j.compedu.2019.103732

Raphael, T. E., \& Au, K. H. (2005). QAR: Enhancing comprehension and test taking across grades and content areas. The Reading Teacher, 59(3), 206-221. https://doi.org/10.1598/RT.59.3.1

Reich, S., Yau, J. C., \& Warschauer, M. (2016). Tablet-based eBooks for young children: What does the research say? Journal of Developmental \& Behavioral Pediatrics, 37(7), 585-591. https://doi.org/10.1097/DBP.0000000000000335

Rockinson-Szapkiw, A. J., Courduff, J., Carter, K., \& Bennett, D. (2013). Electronic versus traditional print textbooks: A comparison study on the influence of university students' learning. Computers \& Education, 63, 259-266. https://doi.org/10.1016/j.compedu.2012.11.022

Salajan, F. D., Schönwetter, D. J., \& Cleghorn, B. M. (2010). Student and faculty inter-generational digital divide: Fact or fiction? Computers \& Education, 55(3), 1393-1403. https://doi.org/10.1016/j.compedu.2010.06.017

Singer, L. M., \& Alexander, P. A. (2017). Reading across mediums: Effects of reading digital and print texts on comprehension and calibration. Journal of Experimental Education, 85(1), 155-172. https://doi.org/10.1080/00220973.2016.1143794

Smith, L. C., \& Mare, N. N. (2011). Reading for today: Issues for today (4th ed.). National Geographic \& Cengage. https://doi.org/10.1080/00220973.2016.1143794

Thong, J. Y. L., Hong, W., \& Tam, K. Y. (2004). What leads to user acceptance of digital libraries? Communications of the ACM, 47(11), 79-83. https://doi.org/10.1145/1029496.1029498

Van den Broek, P., Bohn-Gettler, C., Kendeou, P., Carlson, S., \& White, M. J. (2011). When a reader meets a text: The role of standards of coherence in reading comprehension. In M. T. McCrudden, J. P. Magliano \& G. J. Schraw (Eds.), Text relevance and learning from text (pp. 123-139). Information Age Publishing.

Van den Broek, P., Rapp, D. N., \& Kendeou, P. (2005). Integrating memory-based and constructionist processes 
in accounts of reading comprehension. Discourse Processes, 39, 299-316. https://doi.org/10.1080/0163853X.2005.9651685

Verkijika, S. F. (2019). Digital textbooks are useful but not everyone wants them: The role of technostress. Computers \& Education, 140, 103591. https://doi.org/10.1016/j.compedu.2019.05.017

\section{Copyrights}

Copyright for this article is retained by the author, with first publication rights granted to the journal.

This is an open-access article distributed under the terms and conditions of the Creative Commons Attribution license (http://creativecommons.org/licenses/by/4.0/). 